\title{
A survey of optometrists' ophthalmic medication prescribing
}

This article was published in the following Dove Press journal:

Clinical Optometry

5 March 2014

Number of times this article has been viewed

\section{Agustin L Gonzalez \\ Nikki Bennett \\ Rakesh Lakhani \\ Inter American University, School of Optometry, Bayamón, Puerto Rico}

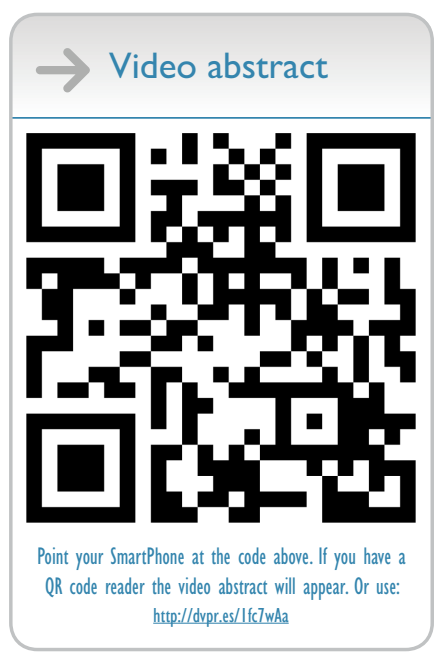

Correspondence: Agustin L Gonzalez 3417 Spectrum Blvd, Richardson, Texas 75082, USA

Email gonzalez.agu@gmail.com
Abstract: Optometry is recognized as a primary care profession within the health care system. For years, much emphasis has been placed on the core function of optometrists as prescribers for refractive correction, yet little is known about their medication prescribing habits. Optometrists have had the ability to prescribe medications for the last 30 years, and still little information is available about optometric pharmaceutical trends. This study consists of a survey aimed at obtaining self-reported data to depict optometrists' likelihood of prescribing ophthalmic medications during a regular clinic day. We conclude that optometrists are indeed using medications in their clinics, and the trends are very similar to the epidemiological distribution of eye disorders in the general population.

Keywords: optometry, prescription drug audit, pharmacoepidemiology

\section{Introduction}

Optometrists were first recognized as physicians in 1986, after Congress approved and President Reagan signed the Omnibus Budget Reconciliation Act of 1986 into legislation. This act contained a resolution for inclusion within the Medicare system (Public Law 99-509).

The first diagnostic pharmaceutical agent law appeared in Rhode Island, USA in 1971, with the first diagnostic therapeutic agent appearing in West Virginia, USA shortly after in $1976 .^{2,3}$ The last state to allow the use of medications for therapeutic purposes for optometric practice was the District of Columbia, USA in 1998.

With the advent of the use of medications, the scope of care for optometry expanded beyond refractive care and into the area of delivering medical care. As such, optometrists with their newfound prescriptive authority were now able to manage and treat diseases of the eye.

Data suggest that optometrists are now prescribing ophthalmic medications at an almost equal rate as ophthalmologists, yet ophthalmologists comprise roughly one-third the number of practicing eye care specialists in the US. ${ }^{4,5}$ There have been authors who have reported increases in upward trends in optometric prescribing habits. These poster presentations have shown that the total increases in the volume of medications prescribed by US optometrists were $6.60 \%$ from $2007-2008$ and $13.63 \%$ from 2008-2009. The same author has documented that optometrists have even increased their prescribing (physical writing of a prescription) of over-the-counter (OTC) products. These findings signal a slow shift and adoption to a more medical-based working environment for optometrists (Gonzalez, unpublished data, poster presentation, American Academy of Optometry, 2010-2011). 
As optometry continues to evolve and expand, the prescribing of medications is starting to play a more important role in the day-to-day life of an optometrist. Data suggest that patients are not visiting their optometrist solely for glasses or contact lenses (Gonzalez, unpublished data, poster presentation, American Academy of Optometry, 2010-2011). Conversely, the management of ocular surface diseases and contact lens complications aids in the retailing of eyewear products.

Furthermore, it has been argued that prescription audits can be used to reflect a group's competence in pharmacological therapy, and these audits may be useful in determining management paradigms and creating policy decisions. ${ }^{7}$

In an effort to better understand the utilization of medications by US optometrists, we developed a self-reporting survey that would ask questions inquiring optometrists' ophthalmic medication prescribing behaviors during an average clinic day.

\section{Methods}

An online-based, self-reporting survey was conducted from September 26, 2012 to October 3, 2012 as part of a project, and was approved by the ethics board. The survey was Webbased. ${ }^{8}$ The authors decided to use a convenience-based sampling method and distributed the survey via email to 81 known practicing optometrists obtained from the primary author's email database. It was also posted on a verified optometry-only online bulletin board (ODwire.org) where it was seen by 429 optometrists.

Our response rate was $21 \%$, based on our sample size of 510 optometrists, and 107 responses were obtained. Assuming that there is a population of 35,000 optometrists currently practicing in the US, this represents a $95 \%$ confidence level. The study has a confidence interval (margin of error) of $9.8 \%$. There was no duplication of responses, and this was tabulated by recording the Internet protocol addresses of the respondents, and matching them to make sure there were no duplicate responses.

The survey was designed by the primary author and it consisted of ten questions, of which the authors decided to report on the first five questions, as these were the most relevant to the topic of this paper.

Both email and posted versions of the survey were worded in an introductory manner to avoid bias on the part of the subject. The survey read:

An optometry student is doing a senior project and has asked me to post this in ODwire. It is a 10 question survey that will take you less than 2 minutes to complete. Here is the link: http://www.surveymonkey.com/s/SMKLNVN.
The first five questions were as follows: Question 1: "Do you have prescriptive authority?"; Question 2: "How long have you practiced Optometry?"; Question 3: "Have you written a prescription for any ophthalmic medications today?"; Question 4: "In a typical day, on average how many times do you write a prescription for an Ophthalmic Medication?"; Question 5: "How likely are you to write a prescription for these medications today?".

Questions 6-9 were on the subject of the number of pharmaceutical sales representatives seen by the office, the number of times these representatives visited the office, the perceived value of the interaction, as well as the optometrists' perceptions of the representatives' knowledge and product presentation, and the optometrists' concerns when prescribing medications.

The first four questions were designed to get a representation of the type of practice and optometrist that are responding. The first question was designed to identify optometrists with prescribing authority; if a respondent answered "no" to the first question, the survey was terminated for that particular participant.

The second question was designed to obtain a sample of the number of years the optometrist was in practice; the third question was designed to verify whether the participant was an active prescriber, or a more casual prescriber; and the fourth question was used to try and see how active our group's prescribing practices were.

The fifth question was based on a Likert-type scale, and it was designed to determine how likely the respondents were to write a prescription for a particular medication. The medications were based on and grouped using the US Food and Drug Administration's general guidelines of groups used and approved for topical use in the eye.

\section{Results}

The survey was answered by 107 anonymous prescribing optometrists who self-reported that they, indeed, had prescriptive authority (Table 1). None of the respondents answered "no", to the first question; therefore, none of the optometrists were deemed ineligible to participate in the study. Of the 107 respondents, $24.3 \%$ had been in practice 7 years or less,

Table I Do you have prescriptive authority?

\begin{tabular}{lll}
\hline Answer options & Response percentage & Response count \\
\hline Yes & $100 \%$ & 107 \\
No & $0 \%$ & 0 \\
Answered question & & 107 \\
Skipped question & & 0 \\
\hline
\end{tabular}


$21.5 \%$ had been in practice between $8-15$ years, $20.6 \%$ had been in practice for $16-24$ years, while $33.6 \%$ had practiced optometry for over 24 years (Table 2). The authors believe this is a good representation of the various generational groups of practicing optometrist.

When we asked the optometrists if they had written a prescription at the time of taking the survey, $24.3 \%$ replied that they had not written a prescription for any medication, while $75.7 \%$ of respondents reported that they had (Table 3 ).

We asked the respondents to report the average amount of prescriptions they would write in a given day; $26.2 \%$ of respondents wrote one or less prescriptions a day, while the majority of respondents (36.4\%) wrote two to three prescriptions in their average day at the clinic. A total of $18.7 \%$ of respondents wrote 4-6 prescriptions, while 20 respondents, accounting for $18.7 \%$ of the responses, wrote seven or more prescriptions a day (Table 4).

In order to find out what our doctors were prescribing, we asked, "How likely are you to write a prescription for these medications?". The answers then ranked by the percentage (Table 5) of responses for "Very likely" and "Somewhat likely", as compared to the overall response rate.

We then proceeded to present the major ophthalmic drug categories by adding the "Very likely" and the "Somewhat likely" responses and calculating the percentage of the population that is likely to prescribe that given medication during their clinic day. The most likely prescribed medications were those in the "dry eye" product category, with $90 \%$ of participants responding that they were "Very likely" or "Somewhat likely" to prescribe within this group. The second most common response pertained to antihistamines with $80 \%$.

Overall, $75 \%$ of respondents in the ophthalmic OTC groups were "Very likely" or "Somewhat likely" to prescribe a product in this category. The fourth and fifth categories of drugs that were most likely to be prescribed were both the combination steroid/anti-infective and anti-infective categories, with $86 \%$ and the anti-infective category with $84 \%$ of respondents very or somewhat likely to prescribe during their clinical day.

Table 2 How long have you practiced optometry?

\begin{tabular}{lll}
\hline Answer options & Response percentage & Response count \\
\hline $0-7$ years & $24.3 \%$ & 26 \\
$8-15$ years & $21.5 \%$ & 23 \\
$16-24$ years & $20.6 \%$ & 22 \\
Over 24 years & $33.6 \%$ & 36 \\
Answered question & & 107 \\
Skipped question & & 0 \\
\hline
\end{tabular}

Table 3 Have you written a prescription for any ophthalmic medications today?

\begin{tabular}{lll}
\hline Answer options & Response percentage & Response count \\
\hline Yes & $75.7 \%$ & 81 \\
No & $24.3 \%$ & 26 \\
Answered question & & 107 \\
Skipped question & & 0 \\
\hline
\end{tabular}

Ophthalmic steroid products were likely to be prescribed by $81 \%$ of respondents (either "Very likely" or "Somewhat likely"). The intraocular pressure (IOP)-lowering category had $54 \%$ of respondents who were "Very likely" or "Somewhat likely" to prescribe these products.

The following categories of prescription medications all showed that fewer than $50 \%$ of respondents were likely to prescribe the following medications during a given day at the clinic. The nonsteroidal anti-inflammatory product group had $36 \%$ of respondents who were "Very likely" or "Somewhat likely" to prescribe these agents. The antiviral product group had $12 \%$ of respondents who were "Very likely" or "Somewhat likely" to prescribe these agents. The antifungal product group showed the lowest value, with only $2 \%$ of respondents indicating that they were "Very likely" or "Somewhat likely" to prescribe these agents (Table 5).

In the last section, there was an opportunity for respondents to record a written response. Some respondents replied in the last section that they could not prescribe these medications, hence the count is less than 107. There were two respondents who did not respond to the antiviral, antifungal, and IOP-lowering agents category items. One of these respondents noted that his or her state had limitations in the prescription of antiviral, glaucoma, and antifungal medications. One respondent did not reply to the anti-infective or steroid medication categories, mentioning that he used combination drops in both instances. Lastly, three respondents noted that they do not write prescriptions for OTC products.

Table 4 In a typical day, on average, how many times do you write a prescription for an ophthalmic medication?

\begin{tabular}{lll}
\hline Answer options & Response percentage & Response count \\
\hline $0-1$ & $26.2 \%$ & 28 \\
$2-3$ & $36.4 \%$ & 39 \\
$4-6$ & $18.7 \%$ & 20 \\
$7-8$ & $14.0 \%$ & 15 \\
Over 8 & $4.7 \%$ & 5 \\
Answered question & & 107 \\
Skipped question & & 0 \\
\hline
\end{tabular}


Table $\mathbf{5}$ How likely are you to write a prescription for these medications today?

\begin{tabular}{lllllll}
\hline Answer options & $\begin{array}{l}\text { Very } \\
\text { likely }\end{array}$ & $\begin{array}{l}\text { Somewhat } \\
\text { likely }\end{array}$ & $\begin{array}{l}\text { Somewhat } \\
\text { unlikely }\end{array}$ & $\begin{array}{l}\text { Very } \\
\text { unlikely }\end{array}$ & $\begin{array}{l}\text { Very or somewhat } \\
\text { likely (\%) }\end{array}$ & $\begin{array}{l}\text { Response } \\
\text { count }\end{array}$ \\
\hline Dry eye product & 64 & 32 & 7 & 4 & 0.90 & 107 \\
Antihistamine & 50 & 36 & 18 & 3 & 0.80 & 107 \\
Ophthalmic over-the-counter & 50 & 28 & 11 & 15 & 0.75 & 104 \\
Combination (anti-infective + steroid) & 45 & 45 & 15 & 2 & 0.84 & 107 \\
Anti-infective & 45 & 46 & 13 & 2 & 0.86 & 106 \\
Steroid & 43 & 43 & 19 & 1 & 0.81 & 106 \\
Intraocular pressure-lowering & 24 & 33 & 28 & 20 & 0.54 & 105 \\
Anti-inflammatory (nonsteroid) & 10 & 28 & 46 & 23 & 0.36 & 107 \\
Antiviral & 3 & 10 & 47 & 45 & 0.12 & 105 \\
Antifungal & 1 & 1 & 17 & 86 & 0.02 & 105 \\
\hline
\end{tabular}

\section{Discussion}

From the data compiled, we can see that a high percentage of the optometrists studied are indeed very likely to prescribe medications for their patients. The most common medications prescribed on a daily basis are for dry eye. This coincides with what we would predict to be most prescribed. Based on the annual dry eye report for $2010,{ }^{6}$ over $50 \%$ of non-contact lens wearers and contact lens wearers do experience dry eye. Perhaps it is evident that optometrists today are comfortable managing dry eye syndrome through medical therapy and through the primary use of OTC eye drops.

It is very common that optometrists consult patients who present with complaints of allergies, as this represents a very common complaint in the general population..$^{9-11}$ A total of $80 \%$ of respondents stated that they are likely to write a prescription for antihistamine medications.

It is interesting to note that $75 \%$ of prescriptions written are for OTC products. This represents a large segment of medications, as it includes both dry eye products and allergy products. The responses would suggest that there is an active recommendation for a specific product.

Other responses pertaining to the types of medications that are prescribed seem to be in line with less often seen eye conditions. In particular, 86 and $84 \%$ of respondents reported they are "Somewhat likely" to prescribe either a combination steroid anti-infective or an anti-infective, respectively. Eighty-one percent (81\%) of the respondents are "Likely" or "Very likely" to prescribe a steroid during their clinic day, while 54\% reported being "Somewhat likely" to prescribe an IOP-lowering agent in the management of glaucoma. An interesting point is that combination drugs were more likely to be prescribed than steroids or anti-infectives alone.

Fungal and viral infections are less commonly seen in clinical practice and, as expected, these medications are the least likely to be prescribed on a daily basis. Only $2 \%$ of respondents reported they are "Very likely" or "Likely" to prescribe an anti-fungal agent, while $12 \%$ reported being "Somewhat likely" or "Likely" to prescribe an antiviral.

It is worth noting that many states have some laws that limit the ability for optometrists to use these medications.

\section{Conclusion}

Although limited, the survey on the self-reported prescribing habits of optometrists is very insightful and points to the fact that a majority of optometrists are indeed reporting using their prescriptive authority as part of their work in their clinical day. It is not surprising that the types of drugs prescribed appear to be prescribed at a rate similar to the incidence of dry eye, allergies, and eye infections.

Although the study has limitations, such as the fact that there are no clear geographical distributions, there is a lack of correlation with current prescribing laws, and the findings do not account for variability in practice settings, it is the first time that optometrists have been surveyed via a self-report about their prescription habits of certain medications.

The authors understand this is a basis for further inferential studies, and agree that more data should be gathered that focus on variables such as practice settings and geography. More information should also be gathered on the number of patient encounters among those optometrists with the highest prescribing trends, their patients' population profiles, and their clinical settings. By studying the process of pharmaceutical utilization by US optometrists, we can gather information that would be helpful in guiding the evolving trends in this field, and in better understanding both the role and impact of optometry in health care.

\section{Disclosure}

The authors report no conflicts of interest in this work. 


\section{References}

1. Department of Health and Human Services USA. Office of Analysis and Inspections. Ophthalmology/Optometry Relationships involving cataract surgery. April 1989. Available from: http://oig.hhs.gov/oei/reports/oai07-88-00460.pdf Accessed January 12, 2014.

2. Goss DA. Why Should Optometrists Know About Their History? Bloomington, IN: Indiana University School of Optometry; 2003. Available from: http://fs.aoa.org/optometry-archives/optometry-timeline.html Accessed January 12, 2014.

3. Cooper SL [webpage on the Internet]. 1971-2011: Forty-year history of scope expansion into medical eye care. St Louis, MO: News from the American Optics Association; 2012. Available from: http://newsfromaoa. org/2012/03/23/1971-2011-forty-year-history-of-scope-expansion-intomedical-eye-care/. Accessed January 14, 2014.

4. Bureau of Labor Statistics, United States Department of Labor [webpage on the Internet]. Occupational outlook handbook, 2012-13 edition, Optometrists. Washington, DC: Bureau of Labor Statistics, United States Department of Labor; 2012. Available from: http:// www.bls.gov/ooh/healthcare/optometrists.htm. Accessed October 03, 2012.
5. Essilor USA (webpage on the Internet). An action-oriented analysis of the state of the optometric profession: 2013. Available from: http://www. aoa.org/Documents/news/state_of_optometry.pdf. Accessed January 14, 2014.

6. Nichols JJ [webpage on the Internet]. 2010 annual report on dry eye disease: a review of current findings and trends in dry eye frequency, diagnosis, and management strategies. Ambler, PA: Contact Lens Spectrum; 2010. Available from: http://www.clspectrum.com/ articleviewer.aspx?articleid=104448. Accessed.

7. Tunis SR, Stryer DB, Clancy CM. Practical clinical trials: increasing the value of clinical research for decision making in clinical and health policy. JAMA. 2003;290(12):1624-1632.

8. SurveyMonkey [homepage on the Internet]. Available from: http://www. surveymonkey.com. Accessed January 22, 2014.

9. Abelson MB, McLaughlin JT, Gomes PJ. Curr Allergy Asthma Rep. 2011;11(3):205-211.

10. Bielory L, Friedlaender MH. Immunol Allergy Clin North Am. 2008;28(1):43-58.

11. Butrus S, Portela R. Ocular allergy: diagnosis and treatment. Ophthalmol Clin North Am. 2005;18(4):485-492.

\section{Clinical Optometry}

\section{Publish your work in this journal}

Clinical Optometry is an international, peer-reviewed, open access journa publishing original research, basic science, clinical and epidemiological studies, reviews and evaluations on clinical optometry. All aspects of patient care are addressed within the journal as well as the practice of optometry including economic and business analyses. Basic and clinical

Submit your manuscript here: http://www.dovepress.com/clinical-optometry-journal

\section{Dovepress}

research papers are published that cover all aspects of optics, refraction and its application to the theory and practice of optometry. The manuscript management system is completely online and includes a very quick and fair peer-review system, which is all easy to use. Visit http://www.dovepress. com/testimonials.php to read real quotes from published authors. 